\title{
Survival into adulthood of patients with atrial isomerism undergoing cardiac surgery
}

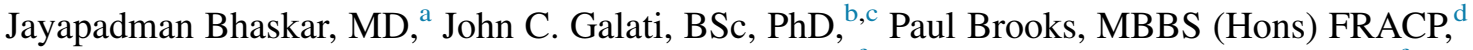 \\ Guido Oppido, MD, ${ }^{\mathrm{e}}$ Igor E. Konstantinov, MD, PhD, ${ }^{\mathrm{a}, \mathrm{f,g}}$ Christian P. Brizard, $\mathrm{MD}, \mathrm{PhD},{ }^{\mathrm{a}, \mathrm{f}, \mathrm{g}}$ and \\ Yves d'Udekem, MD, $\mathrm{PhD}^{\mathrm{a}, \mathrm{f}, \mathrm{g}}$
}

Objectives: To identify determinants of adverse outcomes in patients with atrial isomerism.

Methods: Determinants of survival were analyzed for the group as a whole as well as separately for left and right atrial isomerism.

\begin{abstract}
Results: There were 78 cases with right and 104 with left atrial isomerism. Nineteen patients were not offered surgery; $49(47 \%)$ of those with left atrial isomerism and $60(77 \%)$ with right atrial isomerism were directed to single ventricle palliation. A total of 67 patients died. Survival to 25 years was $62 \%(95 \%$ confidence interval $[\mathrm{CI}], 53 \%-69 \%)$. Independent predictors of mortality were obstructed total anomalous pulmonary venous drainage $(P<.001$; hazard ratio [HR], 5.2; 95\% CI, 2.7-9.7) and asplenia $(P=.008 ; \mathrm{HR}, 2 ; 95 \% \mathrm{CI}, 1.2-3.3)$. There was no evidence that patients born in the recent era had improved survival $(P=.47$; HR, $1.1 ; 95 \% \mathrm{CI}$, 0.8-1.5). Survival was better for patients with left than right atrial isomerism: 18 years survival $74 \%$ (95\% CI, $63 \%-82 \%)$ versus $50 \%(95 \% \mathrm{CI}, 38 \%-60 \%)$. Independent predictors of mortality for patients with left atrial isomerism were dextrocardia $(P=.009 ; \mathrm{HR}, 3.0 ; 95 \% \mathrm{CI}, 1.3-6.7)$ and pulmonary stenosis $(P=.042 ; \mathrm{HR}$, $0.3 ; 95 \% \mathrm{CI}, 0.1-0.9)$ and patients with right atrial isomerism, biventricular repair $(P<.001 ; \mathrm{HR}, 6.0 ; 95 \% \mathrm{CI}$, 2.8-13), and obstructed total anomalous pulmonary venous drainage $(P<.001 ; \mathrm{HR}, 4.2 ; 95 \% \mathrm{CI}, 2.0-8.6)$.
\end{abstract}

Conclusions: A significant proportion of patients with isomerism still die before reaching adulthood. Only a fraction of those with obstructed pulmonary veins survive. Having biventricular repair does not confer a survival advantage to those born with right atrial isomerism. (J Thorac Cardiovasc Surg 2015;149:1509-14)

See related commentary on page 1515

Predictions of survival for patients born with atrial isomerism (ie, heterotaxia) are dismal, and seem worse for those born with right atrial isomerism (ie, heterotaxia/ asplenia) than for those with left atrial isomerism (ie,

From the Departments of Cardiac Surgery ${ }^{\mathrm{a}}$ and Cardiology, ${ }^{\mathrm{d}}$ Royal Children's Hospital, Melbourne, Australia; The Clinical Epidemiology and Biostatistics Unit, ${ }^{\mathrm{b}}$ Murdoch Children's Research Institute, Melbourne, Australia; Department of Mathematics and Statistics, ${ }^{c}$ La Trobe University, Melbourne, Australia; Department of Pediatric Cardiac Surgery, ${ }^{\text {e }}$ S. Orsola-Malpighi Hospital, Bologna, Italy; Department of Pediatrics, ${ }^{\mathrm{f}}$ University of Melbourne, ${ }^{\mathrm{g}}$ Murdoch Children's Research Institute, Melbourne, Australia.

Disclosures: Y.d'U. is a career development fellow of The National Heart Foundation of Australia Research Program (CR 10M 5339) and Australia National Health and Medical Research Council clinician practitioner fellow (1082186). The Victoria government Operational Infrastructure Support Program supported this research project. C.P.B. reports consulting fees from Admedus. All other authors have nothing to disclose with regard to commercial support.

Read at the 94th Annual Meeting of The American Association for Thoracic Surgery, Toronto, Ontario, Canada, April 26-30, 2014.

Received for publication April 11, 2014; revisions received Jan 7, 2015; accepted for publication Jan 21, 2015; available ahead of print March 7, 2015.

Address for reprints: Yves d'Udekem, MD, PhD, Department of Cardiac Surgery, Royal Children's Hospital, Flemington Rd, Parkville, Melbourne, Victoria 3052, Australia (E-mail: yves.dudekem@rch.org.au).

$0022-5223 / \$ 36.00$

Copyright $\odot 2015$ by The American Association for Thoracic Surgery

http://dx.doi.org/10.1016/j.jtcvs.2015.01.038 heterotaxia/polysplenia). The association of several cardiac defects, the complexity of their surgery related to their anomalous systemic and pulmonary venous connections, their disposition to experience dysrhythmias, and the susceptibility of those born with asplenia to experience sepsis all seem to contribute to a large mortality in infancy. ${ }^{1,2}$ There are scarce data enabling us to predict survival beyond adolescence. In recent years, several teams have claimed to have observed an improvement in outcomes in these patients; however, none of these reports present perspectives of survival beyond age 5 years. ${ }^{3-6}$

We reviewed our experience in the Royal Children's Hospital to determine survival expectations to adulthood of patients born with atrial isomerism and predictors affecting this survival.

\section{PATIENTS AND METHODS}

The design of the study was approved by the Royal Children's Hospital Research Ethics Committee and the need for consent was waived because of the retrospective nature of the study. All patients quoted to have atrial isomerism were identified in the hospital database Between 1965 and 2012 a total of 223 patients were identified. Forty-one overseas patients were excluded because of the difficulty to gather their follow-up, leaving 182 as the cohort of this study. Diagnosis of atrial isomerism was made using a combination of echocardiography and catheterization with or without direct operative confirmation of atrial morphology. Seventy-eight patients had right atrial isomerism $(43 \%)$ and 104 were diagnosed with left atrial isomerism (57\%). The 


\section{Abbreviations and Acronyms \\ NYHA $=$ New York Heart Association \\ $\mathrm{TAPVD}=$ total anomalous pulmonary venous drainage}

characteristics of the patients are described in Table 1. Fifty of the 78 patients born with right atrial isomerism had anomalous pulmonary venous connection and 18 of those 50 presented with obstructed total anomalous pulmonary venous obstruction.

\section{Statistical Analysis}

Survival from birth was examined using the Kaplan-Meier estimator of the survival curve. Risk factors for mortality were examined using Cox proportional hazards regression. Factors measured on a continuous scale (including calendar time) were converted to a $z$ score scale for analysis to make estimated hazards ratios more comparable between continuous and binary factors. Due to the relatively small number of deaths ( 27 for left atrial isomerism and 40 for right atrial isomerism), the number of factors included in the multivariable models were restricted to approximately 1 factor per 10 deaths, with preference given to factors with the largest effect sizes (eg, hazard ratio $[\mathrm{HR}]>2.0$ or $\mathrm{HR}<0.5$ ) and strongest evidence against the null hypothesis (lowest $P$ values). All analyses were performed using Stata 12 (StataCorp, College Station, Tex).

\section{RESULTS}

A total of 67 patients with atrial isomerism died during the course of their follow-up. The mean follow-up was $13.8 \pm 9$ years. Overall survival to 25 years of age was $62 \%$ (95\% confidence interval [CI], 53\%-69\%). Independent predictors of overall mortality were obstructed total anomalous pulmonary venous drainage (TAPVD) $(P<.001 ; \mathrm{HR}, 5.2 ; 95 \% \mathrm{CI}, 2.7-9.7)$ and asplenia $(P=.008 ;$ HR, 2; 95\% CI, 1.2-3.3) (Table 2). Only 4 of the 18 patients presenting with obstructed TAPVD achieved late survival. All of them had right atrial isomerism and went along the univentricular pathway. Patients born in the recent era did not have improved survival (HR, 1.1 per 9.5 years progression in calendar time; 95\% CI, 0.8-1.5; $P=.47$ ).

Patients with left atrial isomerism had a much better survival outcome than patients with right atrial isomerism: 18 years survival $74 \%(95 \% \mathrm{CI}, 63 \%-82 \%)$ versus $50 \%$ (95\% CI, 38\%-60\%), presumably due to the higher prevalence of obstructed TAPVD $(23 \%$ for right vs $0 \%$ left) and asplenia ( $73 \%$ for right vs $10 \%$ for left) amongst patients with right atrial isomerism (Figure 1).

\section{Outcomes of Patients With Left Atrial Isomerism}

Of the 104 patients with left atrial isomerism, 14 received conservative management without any surgical intervention. Thirteen patients in this group did not have any cardiac lesions necessitating operative intervention. One patient presenting with Eisenmenger syndrome in the context of a common atrium and high mean pulmonary arterial pressure of $60 \mathrm{~mm} \mathrm{Hg}$ with no additional pathology received
TABLE 1. Patient characteristics

\begin{tabular}{lcc}
\hline \multicolumn{1}{c}{ Morphology } & $\begin{array}{c}\text { Left atrial } \\
\text { isomerism } \\
(\mathbf{n}=\mathbf{1 0 4})\end{array}$ & $\begin{array}{c}\text { Right atrial } \\
\text { isomerism } \\
(\mathbf{n}=\mathbf{7 8})\end{array}$ \\
\hline Dextrocardia & $30(28)$ & $28(36)$ \\
Bilateral superior vena cava & $55(52)$ & $46(59)$ \\
Interrupted inferior vena cava & $93(89.4)$ & $0(0)$ \\
Partial anomalous pulmonary venous & $20(19)$ & $6(8)$ \\
$\quad$ connection & $2(2)$ & $44(56)$ \\
Total anomalous pulmonary venous & & \\
$\quad$ connection & $13(13)$ & $1(1)$ \\
Partial atrioventricular septal defect & $14(14)$ & $71(91)$ \\
Complete atrioventricular septal defect & $35(34)$ & $55(71)$ \\
Double outlet right ventricle & $49(47)$ & $59(76)$ \\
Single ventricle & $32(31)$ & $34(44)$ \\
Pulmonary stenosis & $13(13)$ & $35(45)$ \\
Pulmonary atresia & $24(23)$ & $34(44)$ \\
Right sided aortic arch & $14(13)$ & $3(4)$ \\
Hypoplastic aortic arch & $13(13)$ & 0 \\
Coarctation of the aorta & $9(8.65)$ & 0 \\
Normal intracardiac morphology & $12(11.5)$ & $60(77)$ \\
Documented asplenia & &
\end{tabular}

Values are presented as $\mathrm{n}(\%)$.

conservative management. On last follow-up, at age 14 years, she was alive with New York Heart Association (NYHA) functional class II. Forty of the 90 patients who were offered surgery underwent a biventricular repair and underwent 48 procedures, consisting of atrioventricular septal defect repair $(n=14)$, ventricular septal defect closure $(\mathrm{n}=8)$, aortic arch or coarcation repair $(\mathrm{n}=8)$, atrial septal defect closure $(n=7)$, repair of anomalous pulmonary venous drainage $(n=5)$, resection of subaortic membrane $(\mathrm{n}=4)$, and tetralogy of Fallot repair $(\mathrm{n}=2)$. After a mean of $10.4 \pm 8$ years, there were 6 deaths and the remaining 34 patients were in NYHA functional class I or II.

Fifty patients were directed to univentricular palliation. Forty-four underwent a first palliative procedure at a median age of 54 days consisting of Norwood procedure $(\mathrm{n}=4)$, systemic-pulmonary shunt $(\mathrm{n}=25)$, pulmonary artery banding procedure $(n=15)$, or Damus-Kaye-Stansel procedure $(n=7)$. Detailed outcomes of patients with left atrial isomerism undergoing univentricular palliation are detailed in Figure 2, A. At final follow-up, the 2 patients with bidirectional cavopulmonary shunt and the 26 patients after Fontan were in NYHA functional class I or II.

Forty-one of the 104 cases needed insertion of permanent pacemakers (39\%): 10 for sick sinus syndrome and 31 for conduction abnormalities, including complete heart block/junctional bradycardia/Wenckebach syndrome.

Independent predictors of mortality for patients with left atrial isomerism were the presence of dextrocardia $(P=.009 ; \mathrm{HR}, 3.0 ; 95 \% \mathrm{CI}, 1.3-6.7)$ and pulmonary stenosis $(P=.042$; HR, 0.3; 95\% CI, 0.1-0.9) (Table 3). 
TABLE 2. Predictors of overall mortality

\begin{tabular}{|c|c|c|c|c|}
\hline \multirow[b]{2}{*}{ Variable } & \multirow{2}{*}{$\frac{\text { Univariable }}{P \text { value }}$} & \multicolumn{3}{|c|}{ Multivariable } \\
\hline & & Hazard ratio & 95 $\%$ Confidence interval & $P$ value \\
\hline Obstructed pulmonary veins & $<.001$ & 5.2 & $2.7-9.7$ & $<.001$ \\
\hline PAPVC & .30 & 1.4 & $0.7-3.0$ & .33 \\
\hline Spleen absent & $<.001$ & 2.0 & $1.2-3.3$ & .008 \\
\hline Right atrial isomerism & $<.001$ & 1.1 & $0.5-2.5$ & .76 \\
\hline TAPVC & $<.001$ & 1.3 & $0.6-2.5$ & .53 \\
\hline Patient has asplenia & $<.001$ & 0.9 & $0.2-3.9$ & .85 \\
\hline Pulmonary atresia & .023 & & & \\
\hline Complete atrioventricular canal defect & .031 & & & \\
\hline Male & .059 & & & \\
\hline Spleen on left side & .061 & & & \\
\hline Ladd procedure & .083 & & & \\
\hline Abnormal ventriculoarterial concordance & .100 & & & \\
\hline Right aortic arch & .104 & & & \\
\hline Unknown spleen side & .115 & & & \\
\hline Bradyarrhythmias & .14 & & & \\
\hline Date of birth ( $z$ score $)$ & .16 & & & \\
\hline Dextrocardia or mesocardia & .18 & & & \\
\hline Pulmonary atresia or stenosis & .19 & & & \\
\hline Howell Jolly bodies & .24 & & & \\
\hline Interrupted inferior vena cava & $<.001$ & & & \\
\hline Spleen on right side & .32 & & & \\
\hline No surgery offered (as opposed to biventricular) & .41 & & & \\
\hline Tachyarrhythmia (as opposed to none or unknown) & .43 & & & \\
\hline Pulmonary stenosis & .46 & & & \\
\hline Single ventricle surgical pathway (as opposed to biventricular) & .58 & & & \\
\hline Interrupted aortic arch or coarctation & .62 & & & \\
\hline Bilateral superior vena cava & .86 & & & \\
\hline Diagnosed malrotation (as opposed to normal or unknown) & .90 & & & \\
\hline
\end{tabular}

$P A P V C$, Partial anomalous pulmonary venous connection; TAPVC, total anomalous pulmonary venous connection.

\section{Outcomes of Patients With Right Atrial Isomerism}

Six of the 78 patients with right atrial isomerism surgery were not offered surgery. Five were deemed inoperable and died during the neonatal period. One patient with bilateral superior vena cava, anomalous pulmonary venous connection, pulmonary atresia, and lung circulation dependant of major

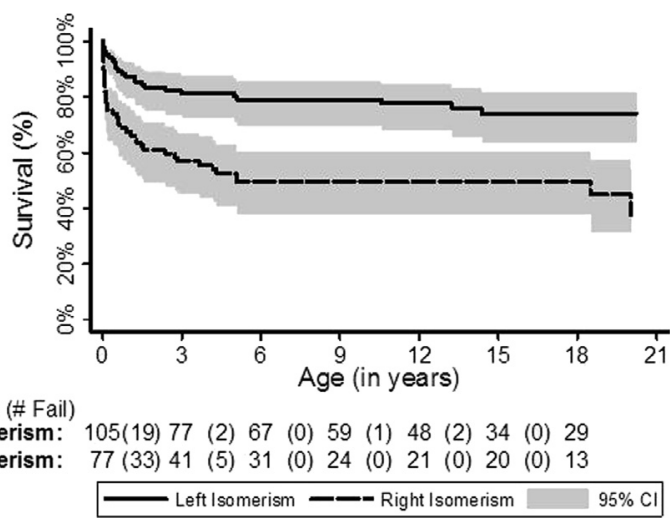

FIGURE 1. Survival (right vs left atrial isomerism). CI, Confidence interval.
\# at Risk (\# Fail) Right Isomerism: aortopulmonary collateral arteries was still alive in NYHA functional class II at age 19 years (final follow-up).

Of the 72 patients who were managed surgically, 60 were directed toward univentricular heart palliation with 35 alive at final follow-up. Their detailed outcomes are displayed in Figure 2, B. At last follow-up, the 8 patients with a bidirectional cavopulmonary shunt status and the 26 with a Fontan status were in NYHA functional class I or II. Of the 12 patients with right atrial isomerism who were directed toward biventricular repair, there was only 1 late survivor. There were 9 perioperative deaths in this group. Eight of these patients were neonates who died after the initial procedure. Seven of these patients underwent operation for obstructed TAPVD (3 associated with a systemicopulmonary shunt and 1 with a Damus procedure and a right ventricle to pulmonary artery conduit). The latter died after the repair of a tetralogy of Fallot with atrioventricular septal defect at age 1 year. The causes of early deaths were low cardiac output $(\mathrm{n}=5)$, pulmonary hypertensive crisis $(\mathrm{n}=3)$, and sepsis $(\mathrm{n}=1)$. Two late deaths were due to noncardiac-related causes (ie, aspiration and necrotizing enterocolitis). Seven of the 78 patients 

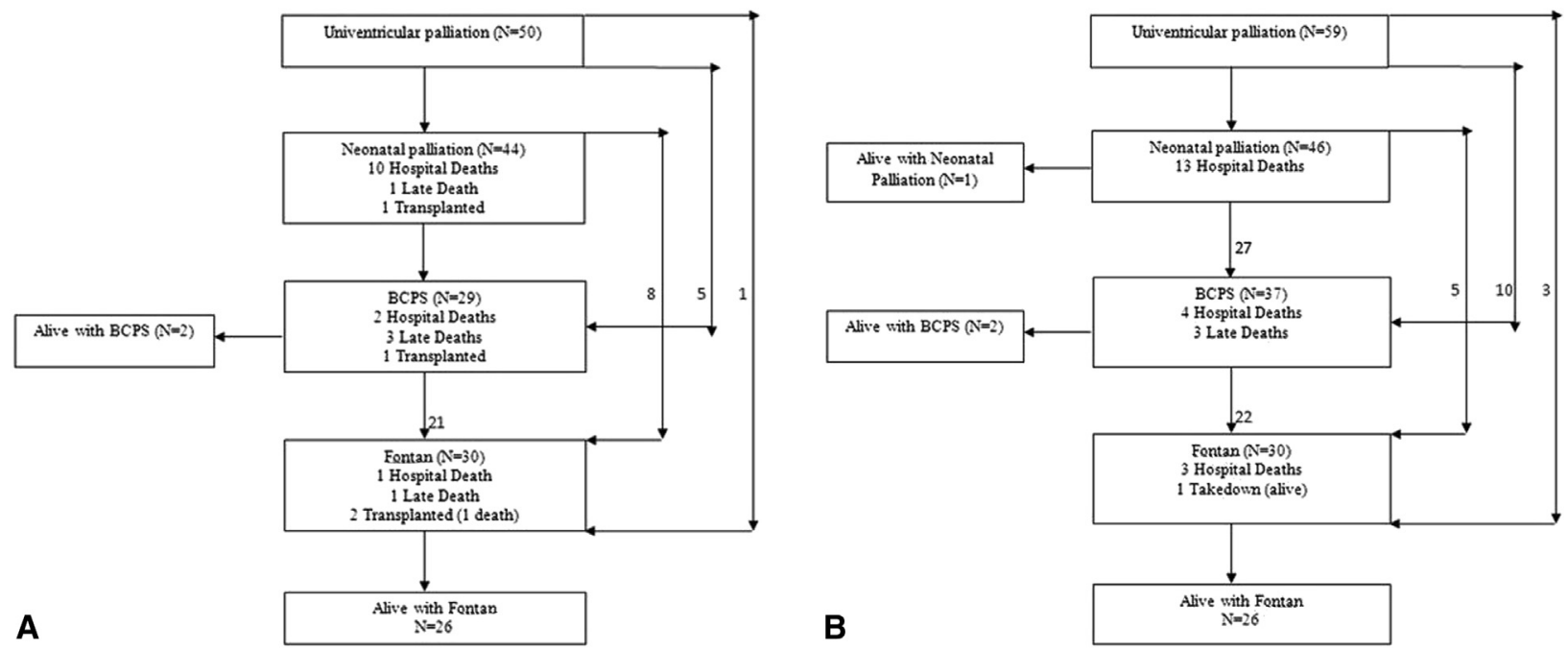

FIGURE 2. A, Pathway and outcomes of patients with left atrial isomerism undergoing univentricular palliation. B, Pathway and outcomes of patients with right atrial isomerism undergoing univentricular palliation. $B C P S$, Bidirectional cavopulmonary shunt.

$(9 \%)$ needed permanent pacemaker implantation: 1 for sick sinus syndrome and 6 for complete heart block. Independent predictors of mortality in patients with right atrial isomerism were being directed to a biventricular repair $(P<.001 ; \mathrm{HR}, 6.0 ; 95 \% \mathrm{CI}, 2.8-13)$ and obstructed TAPVD $(P<.001 ; \mathrm{HR}, 4.2 ; 95 \%$ CI, 2.0-8.6) (Table 3).

\section{DISCUSSION}

The outcomes of patients born with atrial isomerism remain disappointing. Three-quarters of patients born with left atrial isomerism and only one-half of those born with right atrial isomerism will reach adulthood. Similar survival has been described for left atrial isomerism up to age 12 years. $^{7}$ For right atrial isomerism these results

TABLE 3. Predictors of mortality in left and right atrial isomerism

\begin{tabular}{|c|c|c|c|c|}
\hline \multirow[b]{2}{*}{ Variable } & \multirow{2}{*}{$\begin{array}{c}\text { Univariable } \\
P \\
\text { value }\end{array}$} & \multicolumn{3}{|c|}{ Multivariable } \\
\hline & & $\begin{array}{c}\text { Hazard } \\
\text { ratio }\end{array}$ & $\begin{array}{c}95 \% \\
\text { Confidence } \\
\text { interval } \\
\end{array}$ & $\begin{array}{c}P \\
\text { value } \\
\end{array}$ \\
\hline \multicolumn{5}{|l|}{ Left } \\
\hline $\begin{array}{l}\text { Dextrocardia or } \\
\text { mesocardia }\end{array}$ & .047 & 3.0 & $1.3-6.7$ & .009 \\
\hline Pulmonary atresia & .049 & 1.7 & $0.6-4.4$ & .29 \\
\hline Pulmonary stenosis & .098 & 0.3 & $0.1-0.9$ & .042 \\
\hline \multicolumn{5}{|l|}{ Right } \\
\hline $\begin{array}{l}\text { Biventricular surgical } \\
\text { pathway (as opposed } \\
\text { to univentricular) }\end{array}$ & $<.001$ & 6.0 & $2.8-13.1$ & $<.001$ \\
\hline $\begin{array}{l}\text { Obstructed pulmonary } \\
\text { veins }\end{array}$ & $<.001$ & 3.8 & $1.8-7.8$ & $<.001$ \\
\hline Spleen on left side & .062 & 0.2 & $0.1-0.8$ & .026 \\
\hline $\begin{array}{l}\text { No surgery offered } \\
\text { (as opposed } \\
\text { to biventricular) }\end{array}$ & .96 & 0.6 & $0.2-1.7$ & .30 \\
\hline
\end{tabular}

seem better than previously predicted: Survival as poor as $22 \%$ at 14 years has recently been reported and the best perspectives seem previously to have been a survival of $35 \%$ to age 5 years. ${ }^{1,7,8}$ It was disappointing for us to notice that over this long period in this relatively large series for this rare condition no improvement in survival could be noticed with time. In recent years several reports have claimed to have observed an improvement in the survival of patients with right atrial isomerism, but none of them could provide perspectives beyond age 5 years. ${ }^{3-5}$ Although we hope that these improvements in survival will be confirmed in the future, physicians should remain cautious about them as long as the long-term outcome of these patients is not revealed. Improvements have been attributed to a policy of early reintervention of recurrent pulmonary vein stenosis, use of the sutureless repair of anomalous pulmonary venous drainage, and use of smaller systemic-pulmonary shunts to prevent pulmonary hypertension. All of these measures have been applied in our center but failed to result in improved outcomes.

The parameters predicting mortality were already identified in previous studies. The factor that seemed to contribute the most to mortality is the presence of obstructed TAPVD. ${ }^{6,9-13}$ In the series by Eronen and colleagues ${ }^{11} 29 \%$ of patients with TAPVD and right atrial isomerism were inoperable, and the mortality of those undergoing operation was $75 \% .{ }^{11}$ In our series, all of those presenting with obstructed TAPVD who died were patients with right atrial isomerism undergoing univentricular palliation. Therefore, it seems reasonable to attribute this mortality to the deleterious effect of increased systemic pulmonary vascular resistance in a single ventricle circulation. Some have indicated that patients with atrial isomerism are more prone to develop recurrent pulmonary venous stenosis, a fact that may be explained by the higher 
pulmonary venous flow of these patients with a systemicopulmonary shunt or banding. ${ }^{10}$ Asplenia was identified as predictive of mortality, but because only a limited number of our patients died of sepsis, one could wonder whether asplenia is not a surrogate for having a right atrial isomerism and thereby more complex cardiac lesions. We have recently demonstrated that patients with dextrocardia with single ventricle palliation had poor long-term outcomes, although this parameter had not been previously identified as a predictor of mortality. ${ }^{14}$ In our study, we identified that $85 \%$ of patients with dextrocardia and atrial isomerism had atrioventricular regurgitation at the time of presentation. It is possible that the technical difficulty of achieving a sustainable repair in these patients contributed to their mortality. It seems to be corroborated by Anagnostopoulos and colleagues, ${ }^{4}$ who identified atrioventricular valve regurgitation to be a predictive factor for mortality in atrial isomerism.

It was striking to notice that our attempts to achieve biventricular repair in patients with right atrial isomerism failed to the extent that only 1 out of 12 patients survived and that this parameter was independently predictive of mortality in patients with right atrial isomerism. It still seems to us premature to decide that no patients with right atrial isomerism should be directed toward a biventricular repair, but it appears clear that extreme caution should be exerted in these decisions in cases where both approaches could be offered.

\section{Strengths and Weaknesses}

Compared with the previously published literature on the subject, our series is very large and for the first time gives perspectives of survival up to adulthood. The study spans a long time period and slight variation of practice may not have been captured. In this heterogeneous group of patients some parameters contributing to poor outcomes may not have been present in sufficient numbers to be revealed as influencing outcomes.

\section{CONCLUSIONS}

In our experience, there has been no improvement in outcomes after cardiac surgery in patients with atrial isomerism: One-quarter of those with left atrial isomerism and one-half of those with right atrial isomerism still die before reaching adulthood. Despite advances in modern surgical techniques, the outcome of such patients remains poor. Only a fraction of those with obstructed pulmonary veins survive. Undergoing a biventricular repair does not confer a survival advantage to those born with right atrial isomerism.

You can watch a Webcast of this AATS meeting presentation by going to: http://webcast.aats.org/2014/files/ Tuesday/20140429_220PM_240pmPM_Yves_d'Udekem_ Jayapadaman_Bhaskar.mp4.

\section{References}

1. Hashmi A, Abu-Sulaiman R, McCrindle BW, Smallhorn JF, Williams WG, Freedom RM. Management and outcomes of right atrial isomerism: a 26-year experience. J Am Coll Cardiol. 1998;31:1120-6.

2. Gilljam T, McCrindle BW, Smallhorn JF, Williams WG, Freedom RM. Outcomes of left atrial isomerism over a 28-year period at a single institution. J Am Coll Cardiol. 2000;36:908-16.

3. Ota N, Fujimoto Y, Murata M, Tosaka Y, Ide Y, Tachi M, et al. Improving outcomes of the surgical management of right atrial isomerism. Ann Thorac Surg. 2012;93:832-8; discussion 838-9.

4. Anagnostopoulos PV, Pearl JM, Octave C, Cohen M, Gruessner A, Wintering E, et al. Improved current era outcomes in patients with heterotaxy syndromes. Eur J Cardiothorac Surg. 2009;35:871-7; discussion 877-8.

5. Morales DLS, Braud BE, Booth JH, Graves DE, Heinle JS, McKenzie ED, et al. Heterotaxy patients with total anomalous pulmonary venous return: improving surgical results. Ann Thorac Surg. 2006;82:1621-7; discussion 1627-8.

6. Yun T-J, Al-Radi OO, Adatia I, Caldarone CA, Coles JG, Williams WG, et al. Contemporary management of right atrial isomerism: effect of evolving therapeutic strategies. J Thorac Cardiovasc Surg. 2006;131:1108-13.

7. Lim JSL, McCrindle BW, Smallhorn JF, Golding F, Caldarone CA, Taketazu M, et al. Clinical features, management, and outcome of children with fetal and postnatal diagnoses of isomerism syndromes. Circulation. 2005;112:2454-61.

8. Eronen MP, Aittomäki KA, Kajantie EO, Sairanen HI. Outcome of left atrial isomerism at a single institution. Pediatr Cardiol. 2012;33:596-600.

9. Sinzobahamvya N, Arenz C, Reckers J, Photiadis J, Murin P, Schindler E, et al. Poor outcome for patients with totally anomalous pulmonary venous connection and functionally single ventricle. Cardiol Young. 2009;19:594-600.

10. Nakayama Y, Hiramatsu T, Iwata Y, Okamura T, Konuma T, Matsumura G, et al Surgical results for functional univentricular heart with total anomalous pulmonary venous connection over a 25-year experience. Ann Thorac Surg. 2012;93:606-13.

11. Eronen MP, Aittomäki KA, Kajantie EO, Sairanen HI, Pesonen EJ. The outcome of patients with right atrial isomerism is poor. Pediatr Cardiol. 2013;34:302-7.

12. Cheung YF, Cheng VY, Chau AK, Chiu CS, Yung TC, Leung MP. Outcome of infants with right atrial isomerism: is prognosis better with normal pulmonary venous drainage? Heart. 2002;87:146-52.

13. Ohuchi H, Kagisaki K, Miyazaki A, Kitano M, Yazaki S, Sakaguchi H, et al Impact of the evolution of the Fontan operation on early and late mortality: a single-center experience of 405 patients over 3 decades. Ann Thorac Surg. 2011;92:1457-66.

14. Poh CL, Xu M, Galati JC, Iyengar AJ, Cheung M, Brizard CP, et al. Surgical palliation in patients with a single ventricle and dextrocardia. $J$ Thorac Cardiovasc Surg. 2014;148:1475-80.

\section{Discussion}

Dr Glen Van Arsdell (Toronto, Ontario, Canada). Dr Bhaskar and colleagues have tackled a very difficult problem-isomerism. Seventy-four percent of patients who had left atrial isomerism survived to 18 years, and about $50 \%$ of those who had right atrial isomerism survived. It is very nuanced, this disease, and I want to ask 2 questions related to that nuance, mostly right atrial isomerism.

About half of your left atrial isomerism patients wound up with a biventricular heart, about $80 \%$ of your right atrial isomerisms wound up with a univentricular heart, and then of a few who had an attempt of a biventricular repair, ultimately all didn't make it.

This isn't the first time we've seen reports of complex biventricular repairs actually having a worse outcome than single ventricle repairs. I can think of a classic article by Stark from Great Ormond Street about 20 years ago. There is also an article from our group about 10 years ago with similar findings with the double outlet right ventricle.

But it seems to me this is a different disease and a lot of the issue probably is around the total anomalous pulmonary venous return. And the question is the timing of the biventricular repair. Because certainly there are some biventricular repairs that are successful in 
right atrial isomerism. So is this a situation where we should be thinking about staging our treatment of right atrial isomerism if we want to get to a biventricular heart? In other words, doing a veins repair when it is necessary and then coming back at a later date. Are we doing too much at once? Do you have any insight into that?

Dr Bhaskar. That is a good question. As you say, the right atrial isomerism with total anomalous pulmonary venous connection (TAPVC) is a different cohort of patients. Going by the intention-to-treat principle we channeled these patients into a biventricular repair pathway. But of the 12 cases in this cohort, only 2 had a biventricular repair. The others died even before we got to that stage. Although they had 2 good ventricles with adequate size and function, having obstructed TAPVC made managing the disease in these patients more difficult. I'm not quite sure where we can go from here, because we haven't reached the biventricular stage in those patients and they died during the neonatal period. The median survival was just 45 days.

Dr Van Arsdell. Understood. So you were actually already staging these patients and still failed to have success.

Dr Bhaskar. In a way, yes.

Dr Van Arsdell. The second question relates to the problem of neonates with severe obstruction. When I first joined the Hospital for Sick Children, families were given the option of taking their child home to die. Oddly enough they didn't all die. So some parents would say: "Let's go ahead and proceed with surgery." And we would operate on them at age 2, 3, and 4 months and those patients seemed to do well.

Not surprisingly that colored our thinking and we reinstituted therapy with the general principle being if we can stent a vertical vein, if we can make a stented connection between the confluence and the left atrium, if we can accept mild to moderate obstruction and not operate on them, perhaps we can get some of these through. Have you had any opportunity to chase after that, some type of modified strategy to see whether you can improve the outcome for these patients?

Dr Bhaskar. That's a good question, because what we have noticed is that some of these patients may not have clinically evident obstruction of their pulmonary veins. However they become apparent after receiving a systemic to pulmonary shunt, thus snowballing the clinical course of events. From my own experience I cannot comment on any modified strategy. Dr Brizard might want to give his thoughts on this.

Dr Christian Brizard (Parkville, Victoria, Australia). I'm not as familiar as Dr Bhaskar with the data, but we have not recently instituted any alternative strategy for obstructed TAPVC.

Dr Charles Fraser (Houston, Tex). I may have missed it in your presentation, but did you talk about late abdominal complications in this group of patients?
Dr Bhaskar. We did not. Although not highlighted in this presentation, about one-third of the patients had malrotation of the gut, $50 \%$ of whom underwent Ladd procedure.

Dr Fraser. I bring that point up just because we are in the era of segmentalized care. We often forget that these children have significant issues below the diaphragm. What is your policy in Melbourne with regard to prophylactic follow-up of the visceral rotational abnormalities that are often prevalent, and probably even more specific about the liberal use of some sort of protective procedure like a Ladd procedure?

Dr Bhaskar. We don't have a policy for prophylactic Ladd procedure as far as I know; however, these patients are currently seen by the surgical team on a regular basis, providing a holistic approach to management. The database does go way back to the 1970s; however, currently there is no practice of prophylactic Ladd procedure.

Dr Robert Jaquiss (Durham, NC). To follow-up on Dr Fraser's question and in keeping with Dr Backer's liberal use of informal polls of the audience: We struggle with this in our institution. The cardiac surgeons believe a prophylactic Ladd procedure should be done and the pediatric surgeons don't.

When I asked for a show of hands in the audience for how many would arrange for a pediatric surgeon to perform some sort of Ladd procedure when the patient is an asymptomatic child with an isomerism who is known to have malrotation, and how many would observe and wait for a catastrophe, it came out about even. This is the state of the science. It looks like there is a role for a study here.

Dr Christopher Caldarone (Toronto, Ontario, Canada). We all agree that operating on obstructed pulmonary veins is a good idea, but a lot of these patients present with shades of obstruction. It could be that we are waiting for obstruction that's way too obvious and maybe should be decompressing the pulmonary veins much more liberally. What's your threshold for determining whether pulmonary veins are obstructed?

Dr Bhaskar. I think we are guided by the echo findings. We don't have a practice of prophylactic decompression of the pulmonary veins.

Dr Caldarone. So what type of gradient drives you? And of course, you have to take that within the context of what the pulmonary inflow is, which makes it even harder.

Dr Bhaskar. Yes, that makes it even harder, because most of these patients have atresia or pulmonary stenosis and you wouldn't know until you put in a shunt.

Dr Caldarone. And therein lies the trouble.

Dr Brizard. Minimal gradient would trigger surgery on the veins. At the time when the patient is duct-dependent, any acceleration would trigger a surgery on the vein at the time of the palliation. So minimal gradient, yes. 